\title{
Report of A Case of Neck Pain Treated with Trigger Point Dry Needling
}

\author{
Vikrant Bhardwaj ${ }^{1}$, Madhavi Awasthi ${ }^{2}$, Kuljeet Singh Anand ${ }^{3}$ \\ ${ }^{1} \mathrm{PhD}$ Scholar, Faculty of Applied Sciences, Manav Rachna international Institute of Research and Studies, Faridabad, Haryana-121004 \\ (Corresponding Author) \\ ${ }^{2}$ Assistant Professor, Faculty of Applied Sciences, Manav Rachna international Institute of Research and Studies, Faridabad, Haryana-
} 121004

${ }^{3}$ Professor \& Head, Department of Neurology, Dr. RML Hospital, New Delhi-110001

\begin{abstract}
The present case study includes a 40 years old male with a history of neck pain for last 2 days, with no history of trauma or injury, was referred to physiotherapy by orthopedic surgeon with a diagnosis of neck strain of muscular origin. Being a desk job worker by profession, his job involved continuous sitting in front of computer for long hours. The patient presented with severe pain and with reduced range of motion mainly on right side. Following thorough assessment patient was intervened with trigger point dry needling technique. The study revealed that the pain was reduced measured by NPRS (Numeric Pain Rating Scale), increasing the pain pressure threshold as measured by algometer and increase of ROM on right side. The improvement in the restricted range of motion of neck may be a consequence of the decrease in pain and improvement in muscle tone and elasticity after treatment.The results of the present case study can merely assist in providing initial insight for future examining the effectiveness of dry needling, which are currently lacking in the literature.
\end{abstract}

Keywords: Dry needling, trigger point, pain pressure threshold

\section{Introduction}

Neck pain is a very common problem and around two-thirds of the population having this at some point in their lives.Literature reviewed suggest that the main cause of work disabilities is neck pain and sitting at a desk in front of the monitor most of the hours in a day found to be top most cause of neck issues among desk job workers. Human body is not designed for an inactive lifestyle which lead to neck pain due to muscular tightness in both the neck and upper back due to a sustained similar posture for a long duration of time. Similar repeated movements and sustained loading of muscle can cause development of myofascial trigger points (MTrPs) in the muscle.MTrPs are characterized by "a hypersensitive spot, usually electrically active muscle spindles within a taut band of skeletal muscle or in muscle's fascia, they can have a strong focal points of tenderness(Simons, 1996). The thin solid filiform needles can be inserted in to the muscles to de-activate these myofascial trigger points by achieving local twitch response(Dommerholt, Mayoral del Moral and Gröbli2006).

\section{Case Description}

A 40 years old male with a history of neck pain since last 2 days, with no history of trauma or injury, was referred to physiotherapy by orthopedic surgeon with a diagnosis of neck strain of muscular origin. The patient reported neck pain on right paraspinal region in the neck with difficulty in moving the neck on right side. He was a desk job worker by profession, his job involved continuous sitting in front of computer for long hours. The patient reported pain in neck more on right side than the left. The paraspinal muscles in mid neck on the right side were tender during palpation and painful (8/10 on the NPRS) and intensity of pain measured by algometer (model Algo D-01) was $8.5 \mathrm{~N}$ during neck rotation on right side. Notably, the patient also reported a history of similar pain in the past after long shifts of sitting work in front of computer. The patient complained pain during posterior palpation over paraspinal muscles lateral to C-4 \&C-5 level, reported increase in neck pain with active neck rotation and side flexion to the right side. The patient demonstrated more than 50 percent reduction in active range of motion during rotation and side flexion on the right side as compare to the left side. During the initial assessment before treatment, the neck range of motion was measured with an Inclinometer (model Micro FET6) for pre and post treatment readings. The spinous process were marked after palpation. The tender area of the right paraspinal region lateral to $\mathrm{C}-4$ and $\mathrm{C}-5$ spinous process were marked and myofascial trigger point were palpated and marked. The therapist used physical examination to determine the specific as mentioned in the table 1

\section{Intervention}

Before the commencement of intervention an informed consent form was signed by the subject.The marked tender area of the skin was sanitized with alcohol-based chlorhexidine sanitizer and document the number of sites treated.The single sterile solid filiform needle with size of $40 \mathrm{~mm}$ in length and $0.25 \mathrm{~mm}$ in bore, were used to insert in to the skin to release trigger point. The gloves were used to handle needle and it was inserted in to medial and caudal direction with an aim to achieve localized muscle twitch response in the muscle as depicted in the figure 1. Once the needle has been inserted manually into the trigger pointandfirst twitch response was achieved, the needle was pistoned in an up-and-down fashion so that 2- to 3-mm vertical motions occur (ie, fast-in and fast-out technique as described by Hong) at approximately $1 \mathrm{~Hz}$ for 25-30 
seconds. The needle was removed and disposed in the disposal container.

Table 1: Dry needling intervention algorithm for treatment selection

\begin{tabular}{|c|c|}
\hline Assessment & Treatment \\
\hline \multirow{5}{*}{$\begin{array}{c}\text { Trigger point } \\
\text { assessment } \\
\text { performed on the } \\
\text { splenius capitis, } \\
\text { semispinalis } \\
\text { capitis, } \\
\text { semispinalis } \\
\text { cervicis, and } \\
\text { multifidi }\end{array}$} & $\begin{array}{l}\text { Patient in prone, therapist identifies the } \\
\text { hypersensitive spot in the splenius capitis, } \\
\text { semispinalis, spinalis capitis, or multifidi }\end{array}$ \\
\hline & The overlying skin will be cleansed with alcohol \\
\hline & $\begin{array}{l}\text { Once the needle has been inserted manually into } \\
\text { the trigger point, the needle will be pistoned in } \\
\text { an up-and-down fashion so that } 2-\text { to } 3 \text {-mm } \\
\text { vertical motions occur (ie, fast-in and fast-out } \\
\text { technique as described by Hong) at } \\
\text { approximately } 1 \mathrm{~Hz} \text { for } 25-30 \text { seconds, with the } \\
\text { aim of eliciting local twitch responses }\end{array}$ \\
\hline & $\begin{array}{l}\text { After needle is removed, pressure with a cotton } \\
\text { ball will be maintained to prevent any bleeding }\end{array}$ \\
\hline & $\begin{array}{c}\text { The number of sites and specific muscles treated } \\
\text { will be recorded by the therapist }\end{array}$ \\
\hline
\end{tabular}

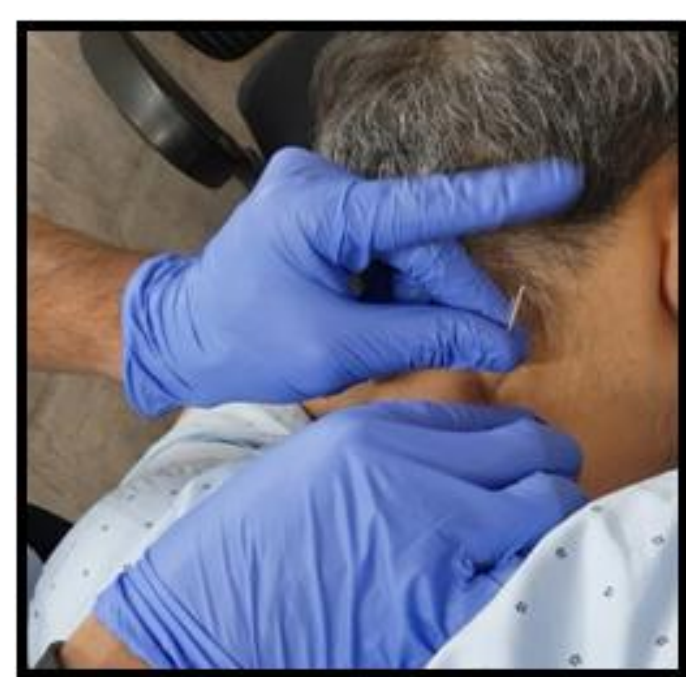

Figure 1: Trigger point dry needling

\section{Outcome}

Immediately following the treatment session, the patient reported a significant reduction in neck pain and was able to move his neck on right side in rotation and side flexion beyond the initial range. The differences were obtained in the measured variable showed better result was a significant reduction of pain (1/10 on NPRS). The neck range of motion was measured again with inclinometer and there was significant increase in range of motion of neck rotation and side flexion on right side.

\begin{tabular}{|c|c|c|c|}
\hline Variable & $\begin{array}{c}\text { Pre- } \\
\text { intervention }\end{array}$ & $\begin{array}{c}\text { Post } \\
\text { Intervention }\end{array}$ & Change \\
\hline NPRS (score) & 8 & 1 & 7 \\
\hline Pain pressure threshold (Newton) & 8.5 & 25.5 & 17 \\
\hline \multicolumn{2}{|c|}{ ROM } \\
\hline Neck Flexion (Degrees) & 45 & 45 & 0 \\
\hline Neck Extension (Degrees) & 15 & 25 & 10 \\
\hline Neck Right side flexion (Degrees) & 10 & 26 & 16 \\
\hline Neck Left side flexion (Degrees) & 30 & 30 & 0 \\
\hline Neck Right Rotation (Degrees) & 15 & 25 & 10 \\
\hline Neck Left Rotation (Degrees) & 70 & 70 & 0 \\
\hline
\end{tabular}

\section{Discussion}

The study revealed that the pain was reduced measured by NPRS, increasing the pain pressure threshold as measured by algometer. The application of trigger point dry needling probably is able to reduce the excitability of the central nervous system by reducing peripheral nociception associated to the trigger point, by reducing dorsal horn neuron activity, and by modulating pain-related brainstem areas (Fernández-de-Las-Peñas and Nijs, 2019). In line with our findings, Pecos-Martin et al investigated the effect of DN on an MTrP of the lower trapezius and observed a higher increase in PPT, compared with a control intervention (De Meulemeester et al., 2017). The improvement in the restricted range of motion of neck may be a consequence of the decrease in pain and improvement in muscle tone and elasticity after treatment.

\section{Conclusion}

The study concludes that the use of dry needling is effective in treating MTrPs and reducing neck pain faster and in turn increasing neck range of motion. As the use of dry needling by physical therapists becomes more widespread, and more therapists are trained in this approach, further researches are needed to support or refute its effectiveness. The results of the present case study can merely assist in providing initial insight for future examining the effectiveness of dry needling, which are currently lacking in the literature.

\section{References}

[1] De Meulemeester, K. E., Castelein, B., Coppieters, I., Barbe, T., Cools, A., \&Cagnie, B. (2017). Comparing trigger point dry needling and manual pressure technique for the management of myofascial neck/shoulder pain: a randomized clinical trial. Journal of manipulative and physiological therapeutics, 40(1), 11-20.

[2] Dommerholt, J., Mayoral del Moral, O. and Gröbli, C., 2006. Trigger point dry needling. Journal of Manual \& Manipulative Therapy, 14(4), pp.70E-87E.

[3] Fernández-de-Las-Peñas, C., \&Nijs, J. (2019). Trigger point dry needling for the treatment of myofascial pain syndrome: current perspectives within a pain neuroscience paradigm. Journal of pain research, 12, 1899.

[4] Simons, D.G., 1996. Clinical and etiological update of myofascial pain from trigger points. Journal of musculoskeletal pain, 4(1-2), pp.93-122. 